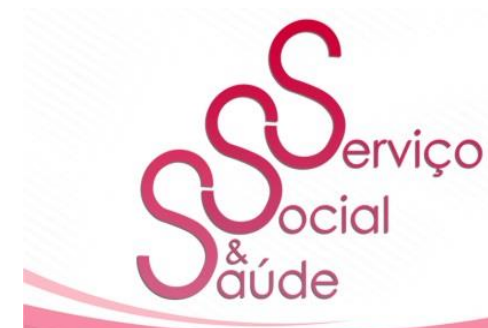

\title{
Limites e contradições do uso de tecnologias digitais em saúde no contexto da pandemia da CoviD-19 no Brasil
}

\author{
Limits and contradictions in the use of digital health technologies in the context of COVID-19 \\ pandemic in Brazil
}

\author{
Marcilio Sandro de Medeiros ${ }^{1}$ \\ Lauro Borges ${ }^{2}$ \\ José Evangelista Torres Filho \\ Regina Célia Borges de Lucena ${ }^{4}$
}

\section{RESUMO}

As narrativas e formas de comunicação virtual durante a pandemia de COVID-19 expressam, em grande medida, os conflitos políticos e sociais que permeiam o sistema de saúde brasileiro e a própria estrutura econômica e social do país. Logo, os recursos para o enfrentamento da pandemia devem também contemplar os impasses oriundos desses conflitos e suas formas de expressão pela sociedade. Este ensaio objetiva discutir limites e contradições entre exposição e privacidade no uso de tecnologias digitais de informação e comunicação em saúde na esfera pública, no contexto da pandemia de COVID-19 no Brasil. Trata-se de uma pesquisa do tipo exploratória pautada em revisão de literatura, bem como na consulta a notícias e documentos legais relacionados com a temática. Os resultados

\footnotetext{
${ }^{1}$ Doutor em Direitos Humanos, Saúde Global e Políticas da Vida pela Fundação Oswaldo Cruz (Fiocruz) /Universidade de Coimbra. Pesquisador do Laboratório Território, Ambiente, Saúde e Sustentabilidade do Instituto Leônidas e Maria Deane (ILMD) - Fiocruz Amazônia. Docente do Instituto Aggeu Magalhães, FIOCRUZ Pernambuco e Coordenador do Projeto Plataforma Digital Colaborativa da Prevenção e Vigilância das Violências VPPIS-001-FIO18, Edital Ideias Inovadoras do Programa Inova Fiocruz. Telefone: (92) 36212323. E-mail: marcilio.medeiros@ fiocruz.br

${ }^{2}$ Graduado em Ciência Política e Relações Internacionais pela Universidade da Beira Interior, Portugal e Mestre em Estratégia pela Universidade de Lisboa, Portugal. Membro colaborador do Projeto Plataforma Digital Colaborativa da Prevenção e Vigilância das Violências VPPIS-001-FIO18, Edital Ideias Inovadoras do Programa Inova Fiocruz. E-mail: laurojovem90@gmail.com

${ }^{3}$ Graduado em Comunicação Social pela Universidade Federal do Amazonas. Bolsista da Fundação de Apoio à Fiocruz (FIOTEC), no Projeto Plataforma Digital Colaborativa da Prevenção e Vigilância das Violências VPPIS001-FIO18, Edital Ideias Inovadoras do Programa Inova Fiocruz, do ILMD - Fiocruz Amazônia. Email: zecatorres1955@gmail.com

${ }^{4}$ Biomédica. Doutora em Política Social pela Universidade de Brasília (UnB). Servidora na Agência Nacional de Vigilância Sanitária no cargo de Especialista em Regulação e Vigilância Sanitária. Docente da Universidade Federal do Recôncavo da Bahia. E-mail: regina.lucena@anvisa.gov.br
} 


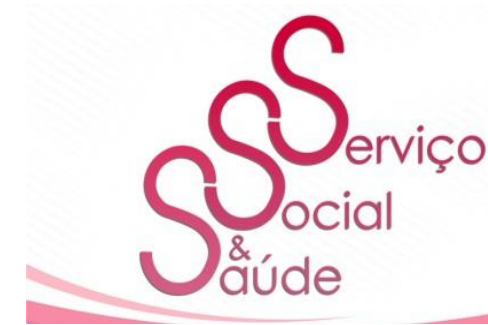

mostraram que as questões relacionadas à informação e comunicação em saúde têm influenciado comportamentos sociais, com manifestações contraditórias sobre a doença nas redes sociais, de medo e de negação, que geram narrativas capazes de potencializar vulnerabilidades e com impactos negativos sobre os serviços de saúde. Por outro lado, há controvérsias sobre o uso de dados em tecnologias digitais para o combate à pandemia, quanto a questões éticas e legais relacionadas a esse processo. Tais questões apontam para a importância de estabelecer políticas de informação e comunicação, na perspectiva de vigilância em saúde, que possibilitem a construção de uma participação que esteja assentada na solidariedade e em contribuições efetivas para a solução dos problemas coletivos.

PALAVRAS-CHAVE: Redes Sociais na Saúde Pública. Proteção de Dados. COVID-19.

\section{ABSTRACT}

The narratives and forms of virtual communication during the Covid-19 pandemic express, in a large extent, the political and social conflicts that permeate the Brazilian health system and its economic and social structure. Therefore, the resources to face the pandemic must also include the gridlocks arising from these conflicts and their forms of expression by society. This essay aims to discuss the limits and contradictions between exposure and privacy in the use of digital health information and communication technologies in the public sphere, in the context of the Covid-19 pandemic in Brazil. This is an exploratory research based on literature review, as well as consulting news and legal documents related to the theme. The results showed that issues related to health information and communication have influenced social behaviors, with contradictory manifestations about the disease in social networks, of fear and denial, which generates narratives capable of reinforcing vulnerabilities and with negative impacts on health services. On the other hand, there are controversies about the use of data in digital technologies to combat the pandemic, regarding ethical and legal issues related to this process. Such questions point to the importance of establishing information and communication policies, from the perspective of health surveillance, that enable the construction of participation based on solidarity and effective contributions to the solution of collective problems.

KEYWORDS: Social Networking. Computer Security. COVID-19.

\section{INTRODUÇÃO}

$A$ pandemia de COVID-19, identificada pela primeira vez em Wuhan/China, no ano de 2019, tem sido um enorme desafio sanitário em vários países. No Brasil, 12 meses após o primeiro caso, a gestão da pandemia tem sido marcada por uma condução polêmica e não organizada por parte do Governo Federal, sem diretrizes estratégicas e com desarticulação das ações interfederativas (IPEA, 2021), uma construção que Freitas e col. (2021) denominam de “desamparo público”. A essas dificuldades de gestão, somam-se problemas de outras ordens, como os gerados pelo uso de dados pessoais e pela midiatização de questões de saúde, num

\begin{tabular}{|l|l|l|l|l|l|r|} 
Serv. Soc. \& Saúde & Campinas, SP & v. 20 & $1-15$ & e021002 & 2021 & e-ISSN 2446-5992 \\
\hline
\end{tabular}




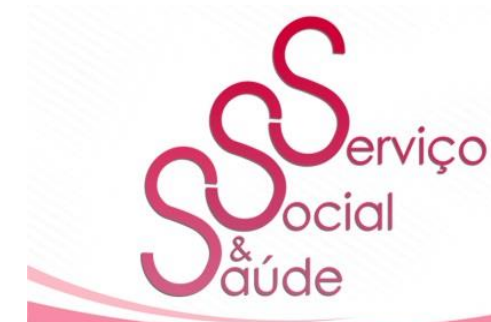

ISSN 2446-5992

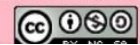

10.20396/sss.v20i00.8665391

contexto de uso massivo de tecnologias digitais e redes sociais. Tais questões remetem ao sistema de representação social que, segundo Samaja (2004), constitui uma das três dimensões de análise da saúde pelas Ciências da Saúde, ao lado dos problemas e das estratégias de ação, no âmbito da categoria da Reprodução Social, aplicada a interpretar os fenômenos sanitários (YNOUB; SAMAJA, 2008).

As representações sociais são entendidas como um mecanismo de representação dos estados objetivos e subjetivos nos quais o indivíduo se encontra, e dos estados que outros indivíduos esperam alcançar. Esse alcance ocorre, em primeiro lugar, mediante linguagem, em segundo lugar, mediante a escrita, e em terceiro lugar, mediante a livre produção de novos objetos mediante a experimentação e simulação possibilitada pela virtualidade no ciberespaço. $\mathrm{Na}$ atualidade, as representações sociais têm no poder midiático um importante vetor de produção das representações e dos sentidos, as quais se reproduzem os indivíduos e as instituições sociais. Esses processos se configuram em uma dada comunidade falante humana que se forma e se transforma no mesmo processo em que regula (quer dizer, reordena ou ressignifica) a conduta de cada indivíduo na esfera pública (SAMAJA, 2004; YNOUB e SAMAJA, 2008).

O conceito de esfera pública política é fortemente relacionado às questões de participação política, pois pressupõe uma estrutura comunicacional a partir da relação entre os interesses da sociedade civil e o poder político estatal (ROSA; LUIZ, 2011). Para alguns autores, esse conceito, embora expresse a importância dos espaços sociais para a prática democrática, deve reconhecer também a ideia de luta política e disputa pelo poder que integra o modelo de Estado centrado no neoliberalismo. Na abordagem neoliberal, “o Estado é uma instituição ineficaz, deficitária e perniciosa para o desenvolvimento econômico e, por isso, deve se restringir-se à manutenção da ordem, da liberdade e da propriedade privada, bem como assegurar condições para o livre mercado" (BORLINI, 2010, p. 321). Esse modelo resultou em obstáculos estruturais para a construção do bem-estar social e consolidação das políticas de saúde, sob a lógica do acesso vinculado à estrutura social vigente e em razão das muitas contradições entre público e privado. 


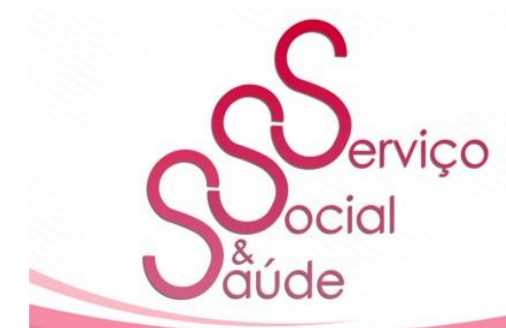

ISSN 2446-5992

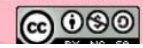

10.20396/sss.v20i00.8665391

De acordo com Jovchelovitch (2000), as representações sociais são fenômenos simbólicos produzidos na esfera pública, como resultado de determinadas condições sócio históricas que levam à construção simbólica dos espaços públicos. De acordo com a autora, “"a vida pública, com suas instituições específicas, seus rituais e significados, é o topo [lugar] no qual as representações sociais desenvolvem-se e adquirem existência concreta. Quando isso ocorre às representações sociais, elas mesmas tornam-se constitutivas da vida pública" (JOVCHELOVITCH, 2000, p. 82).

Nesse sentido é que essas representações se traduzem, muitas vezes, em sociabilidades que desafiam o modo de fazer a vigilância em saúde e que agem na determinação de situações de saúde. As narrativas e formas de comunicação durante a pandemia de COVID-19 expressam, em grande medida, os conflitos entre público e privado que permeiam não apenas o sistema de saúde brasileiro, mas a própria estrutura econômica e social do país. Logo, os recursos para o enfrentamento da pandemia devem também contemplar os impasses oriundos desses conflitos e suas formas de expressão pela sociedade. Este ensaio tem por objetivo discutir limites e contradições entre exposição e privacidade no uso de tecnologias digitais de informação e comunicação em saúde na esfera pública, no contexto da pandemia de Covid-19 no Brasil.

\section{MEDO E NEGAÇÃO EM TEMPOS DE PANDEMIA}

O exibicionismo, aqui entendido como exposição da vida privada e do seu universo simbólico, é uma das expressões da capitalização da vida privada no capitalismo conexionista. A nova configuração da relação entre público e privada nesse novo espírito do capitalismo incluiu a exibição de si nas redes sociais como parte da apropriação da vida privada como mercadoria (THIBES, 2017). Como observado por Ribeiro (2020, p. 3), “a pandemia do coronavírus é a primeira que se vive no tempo on-line”, com potencialização do chamado espaço-público-virtual. Isso remete à centralidade da comunicação na esfera pública midiatizada, que torna as relações sociais mais dinâmicas e imprevisíveis. 


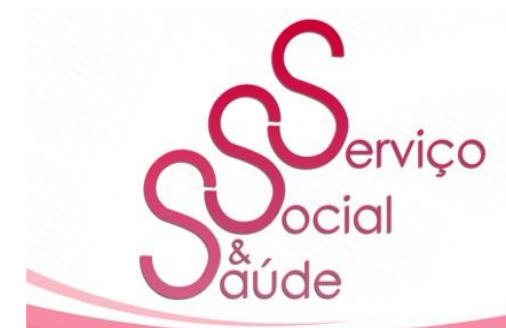

\section{ISSN 2446-5992}

(c) (1) (2)

10.20396/sss.v20i00.8665391

5

No contexto brasileiro, essa midiatização hiperconectada, ao lado de uma conjuntura político-social conturbada, extremista e marcada pela intolerância, pode causar danos a indivíduos e à coletividade. Uma das manifestações desse processo é a exposição pública do estado de saúde nas redes sociais. No caso do COVID-19, uma doença respiratória provocada por um vírus com enorme capacidade de disseminação, representa uma ameaça grave à vida, o que inaugura, na constatação de Ribeiro (2020, p. 1), "uma nova classe de medo global." Dessa forma, o estigma e discriminação se tornaram uma preocupação como parte da resposta ao COVID-19.

Nessa direção, o Programa Conjunto das Nações Unidas sobre vírus da imunodeficiência humana/síndrome da imunodeficiência adquirida - HIV/AIDS (UNAIDS), com base na experiência de resposta à AIDS, divulgou recomendações baseadas em evidências sobre a redução do estigma e da discriminação. A justificativa para essa divulgação é a presença do estigma específico a certas condições de saúde, que foi observado em situações anteriores, como os surtos de Ebola e do vírus Zika, também na pandemia da COVID-19.

Esse estigma se concretizou por meio de manifestações de xenofobia dirigida a pessoas consideradas responsáveis por trazer a COVID-19 para os países, ataques as profissionais de saúde, além de abuso verbal e físico contra pessoas que se recuperaram da doença. Também foram relatados ataques a populações que enfrentam estigma e discriminação pré-existentes, incluindo pessoas vivendo com HIV, minorias de gênero, minorias sexuais, profissionais do sexo e migrantes (UNAIDS, 2020). Ao analisar os impactos da COVID-19 na população negra e em grupos vulnerabilizados específicos, Santos e colaboradores (2020) verificaram que esses grupos populacionais estão entre os mais atingidos pela doença, inclusive com maior risco de morte, o que demonstrou que as respostas inadequadas à pandemia no país ampliaram a vulnerabilidade de populações historicamente discriminadas.

Por outro lado, como resultado da narrativa do Governo Federal quanto à gravidade do problema, as reações e ações de enfrentamento passaram a ser vistas como "sinal de 'histeria', 


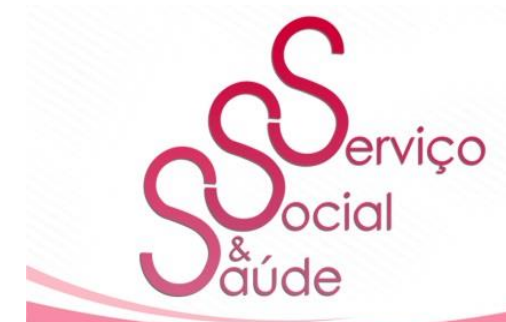

ISSN 2446-5992

(c) 10 (2)

10.20396/sss.v20i00.8665391

uma vez que a pandemia era tida como uma 'fantasia' e que se defendia que a COVID-19 não passava de uma 'gripezinha', como afirmou o Presidente da República, em março [de 2020]” (BOULLOSA et al., 2021, p. 77). Essa narrativa fortalece uma representação diametralmente oposta ao medo, à negação, por meio da disseminação de desinformação e da exposição pública de comportamentos de risco e discursos desfavoráveis às medidas de controle (CALIL, 2021). Essas manifestações se apoiaram geralmente no princípio da liberdade de expressão e de outras liberdades individuais, como liberdade de escolha, liberdade de ir e vir etc. Portanto, essas variáveis tornaram a situação mais grave no que diz respeito à possibilidade de prevenção e consequente sobrecarga de serviços de saúde.

Nas sociedades capitalistas, ser 'livre' é um direito almejado por todos, a ser usufruído e, mais recentemente, publicizado a partir da esfera privada. Dessa forma, transformou-se em uma qualidade orientada para a ampliação das possibilidades de escolha, de expressão e de realização individual, como explica Medeiros (2017), aplicado ao problema da violência no trânsito quando o indivíduo assume o risco de matar ou morrer ao dirigir sobre efeito do álcool. No entanto, trata-se da configuração de uma sociedade de indivíduos, onde o principal indicador subjetivo e social é a referência a si, ou seja, um movimento de profunda individualização de valores (BENDASSOLLI, 2000). É nessa direção que a pandemia de Covid-19 entra em rota de colisão com esses princípios, devido à necessidade de valores coletivos, diante da crise humanitária apontada por Lima e colaboradores (2020), em razão da organização social que prevalece atualmente:

[...] globalizada nas trocas econômicas, mas enfraquecida como projeto político global, interconectada digitalmente, porém impregnada de desinformação, à beira de colapso ambiental, mas dominantemente não sustentável, carente de ideais políticos, mas tão avessa à política e a projetos comuns (LIMA e col., 2020, p. 1). 


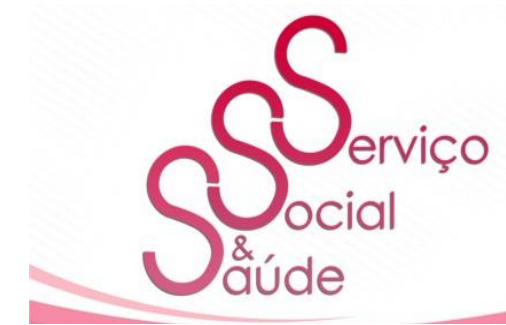

ISSN 2446-5992

(๑⿻)

10.20396/sss.v20i00.8665391

A SUPERVALORIZAÇÃo DO INDIVÍDUO E AS REPERCUSSÕES SOBRE O CUIDADO EM SAÚDE

De acordo com Mattos (2016), na teoria liberal, a liberdade é vista sob uma perspectiva individualizante, isolada da dimensão coletiva e do campo da política e do agir comum. A supervalorização da individualidade na esfera privada promove um distanciamento cada vez maior dos indivíduos em relação aos problemas coletivos, o que se verificou também nessa experiência mundial da pandemia da COVID-19. No entanto, observa-se, de forma progressiva, as desigualdades na vulnerabilidade à doença que, como observa Nunes (2020), embora seja um fato social global, não é uma única pandemia e está vinculada a relações políticas desiguais na sociedade.

Ao mesmo tempo, a pandemia acontece num momento da humanidade em que as mídias digitais se constituem como uma das mais importantes agências de construção dos sentidos sociais, que influenciam na formação dos valores, escolhas e atitudes dos sujeitos. A exposição pública de dados pessoais sensíveis de saúde nas redes sociais pode reforçar a ideia de liberdade no âmbito da esfera privada, o que estimula a sensação de "direito" à exibição.

Nesse sentido, cabe reforçar a importância do sigilo dos dados pessoais, especialmente os sensíveis, que registram nossas escolhas, opções e posicionamentos em relação a outras pessoas e a coisas do mundo em que vivemos. Trata-se de registros individuais sobre temas como autodeterminação racial ou étnica, convicção religiosa, opinião política, filiação a sindicato ou a organização de caráter religioso, filosófico ou político, ou mesmo dados referentes ao estado de saúde, à vida sexual, genéticos ou biométricos.

Isso acontece em decorrência das novas possibilidades de notificação e registro de nascimento, adoecimento, internação, exames laboratoriais. Mais recentemente, também são objetos de preocupação os prontuários eletrônicos utilizados pela telessaúde, assim como formulários eletrônicos de registro de queixas relativas à saúde usados em aplicativos de smartphones, o que hoje se denomina de infovigilância (LEAL-NETO e col., 2016).

Loch (2007) assegura que, na área de saúde, o segredo profissional adquiriu fundamentação mais rigorosa na atualidade, pela urgência de se resguardar as necessidades e 


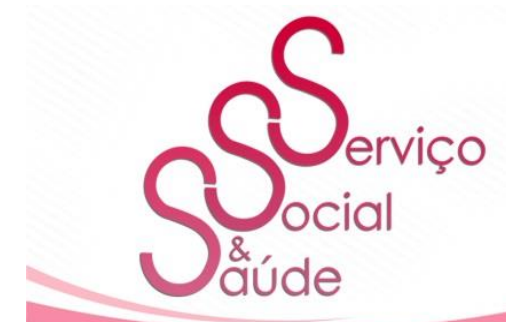

ISSN 2446-5992

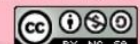

10.20396/sss.v20i00.8665391

\section{8}

direitos dos cidadãos à intimidade, passando a ser entendido como confidencialidade. Assim sendo, a intimidade está conceitualmente relacionada à privacidade, onde esta última é vista sob dois enfoques distintos: o primeiro centrado no controle que o indivíduo exerce sobre o acesso de outros a si próprio; e o segundo define a privacidade como uma condição ou estado de intimidade. Ainda segundo a autora, a informação em saúde pode ser considerada como a mais íntima, pessoal e sensível das informações sobre uma pessoa, tendo em vista que os dados gerados pela realização da anamnese e do exame físico são como uma extensão do corpo ou da mente de alguém.

Esses aspectos remetem ao direito à privacidade, a segunda geração de direitos outorgada na Declaração Universal dos Direitos Humanos. Nesse sentido, as estratégias de segurança digital de arquivamento de dados sensíveis se materializam por meio das técnicas de processamento automatizado de dados e das técnicas de criptografia que asseguram a coleta, guarda e manuseio dos dados pessoais e dos dados sensíveis. Aliado a isso, há o aumento de amparo legal propiciado por normas e notas técnicas publicadas pelos conselhos de classe dos profissionais de saúde, no intuito de assegurar o segredo profissional aos pacientes.

Portanto, o debate sobre a dupla natureza do conceito de segredo profissional, o direito-dever, na medida em que é reconhecido como um direito do paciente gera um novo desafio para profissionais da saúde: o enfrentamento da midiatização inerente à vida moderna. Tais questões atravessam o ambiente hospitalar e espaços de cuidado, por meio do fenômeno do 'eu registro, eu público' e das selfies, que são uma espécie de exposição pública em que o autor se autorretrata e retrata a situação em seu entorno. As imagens registradas podem incluir fotos e vídeos de doentes, cirurgias e cadáveres, feitas por dispositivos do tipo smartphones e publicadas instantaneamente nas redes sociais, a despeito de possíveis sanções administrativas e jurídicas aos autores e profissionais de saúde envolvidos.

A exibição de si ou do outro em redes sociais e outros meios digitais transgride, portanto, a noção do direito à privacidade, no rastro do esmaecimento dos contornos da vida privada na sociedade da informação. Nesse sentido, Martorell e col. (2016) alertam para a 


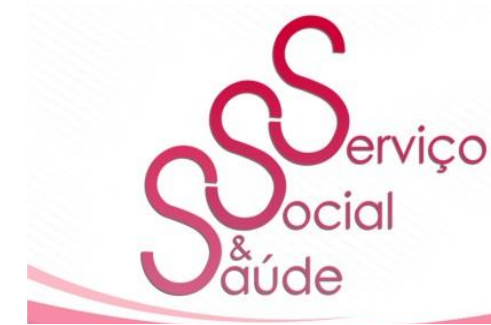

ISSN 2446-5992

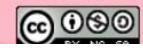

10.20396/sss.v20i00.8665391

banalização de rotinas, práticas e, até mesmo, da figura humana, que pode trazer repercussões negativas para profissionais, pacientes e toda a sociedade, além de infringir diretamente os direitos humanos universais. É ainda mais complexo lidar com essas questões num momento de pandemia, com sobrecarga dos serviços e profissionais de saúde e sem diretrizes nacionais claras sobre as questões de informação e comunicação.

\section{O USO DE DADOS PESSOAIS PARA O CONTROLE DE EPIDEMIAS}

A resposta global à pandemia da COVID-19 incluiu tantas medidas quarentenárias foram consolidadas no século XIV, quanto o aparato contemporâneo de informação e comunicação recentemente desenvolvido, como geolocalização, drones, câmeras de monitoramento e as estratégias de vigilância genômica (LIMA e col., 2020). Muitos países, principalmente no continente asiático, usaram essas ferramentas desde o período inicial do surto, de forma bem-sucedida (GRASSI; PINTO, 2021). Aplicativos de geolocalização, por exemplo, contribuem para o cumprimento do isolamento social e mapear a transmissão da doença e surgimento de novos casos. Essa utilização não ficou isenta de debates e questionamentos sobre a gestão dessas ferramentas, possibilidades de uso indevido dos dados e, principalmente, controvérsias sobre ao limite da intervenção estatal no direito à privacidade e à proteção de dados dos indivíduos.

No Brasil, destacam-se duas medidas emblemáticas desses debates, que resultaram em embates entre governo e sociedade e não utilização massiva dessas ferramentas. São eles: (i) o projeto de geolocalização proposto pelo Ministério de Ciência, Tecnologia, Inovações e Comunicações, que consistia no compartilhamento de localização de telefones celulares para identificar se há aglomerações e situações de risco de contaminação pelo vírus. O uso dessas informações foi vetado, em abril de 2020, pelo Presidente da República e o projeto foi suspenso (BUCCO, 2020); e (ii) a Medida Provisória $\mathrm{n}^{\circ}$ 954/2020, que determinava o compartilhamento de cadastros dos clientes de operadoras de telefone com o Instituto Brasileiro de Geografia e Estatística (IBGE), vetada pelo Supremo Tribunal Federal em maio de 2020 (STF SUSPENDE, 2020).

\begin{tabular}{|l|l|l|l|l|l|r|} 
Serv. Soc. \& Saúde & Campinas, SP & v. 20 & $1-15$ & e021002 & 2021 & e-ISSN 2446-5992 \\
\hline
\end{tabular}




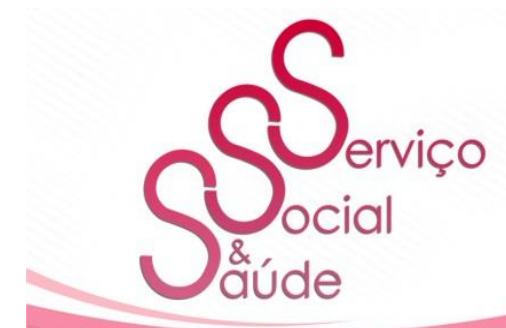

\section{ISSN 2446-5992}

(c) (1) (2)

10.20396/sss.v20i00.8665391

Ainda no contexto nacional, houve a entrada em vigor, em setembro de 2020, da Lei Geral de Proteção de Dados Pessoais (LGPD), Lei n $13.853 / 2019$. Fundamentada em valores de respeito à privacidade, liberdade de expressão, livre iniciativa e defesa do consumidor, a Lei estabelece responsabilidades e procedimentos para o tratamento de dados pessoais e compartilhamento com terceiros.

Inicialmente prevista para fevereiro de 2020, uma medida provisória editada em abril do mesmo ano tentou adiar o início da entrada em vigor da LGPD para 2021, mas o Senado rejeitou a alteração. Desde a publicação da Lei, a adequação do governo e do empresariado para adequação às novas regras foi marcada pela inércia e pela insuficiência de implantação dos requisitos necessários ao seu cumprimento. No entanto, a postergação teria impactos negativos para o país, inclusive quanto à repercussão internacional, particularmente num momento de relevância do tema, em razão do combate à pandemia (JUNQUEIRA; CHALFIN, 2020).

Não obstante, a existência de um arcabouço normativo robusto como a LGPD pode não ser, por si só, suficiente para a sua efetiva utilização em medidas e tecnologias para o combate ao COVID-19. De acordo com Almeida e colaboradores (2020), isso requer a existência de recursos materiais (tecnologia, infraestrutura) e pessoal especializado. Além disso, o monitoramento das atividades é necessário inclusive para a aplicação do princípio de responsabilização, quando necessário, com as sanções cabíveis.

\section{CONSIDERAÇÕES FINAIS}

$\mathrm{Na}$ análise sobre representações sociais e esfera pública durante a pandemia, destacamos três questões relacionadas à informação e comunicação em saúde, que têm permeado novas sociabilidades. O primeiro é o impacto desses comportamentos sobre dos serviços de saúde, que já enfrentam a sobrecarga oriunda do colapso do sistema em face do quadro da pandemia no país. O segundo ponto é que, entre essas sociabilidades, coexistem manifestações sobre a doença nas redes sociais, de negação e de exibicionismo, que geram 


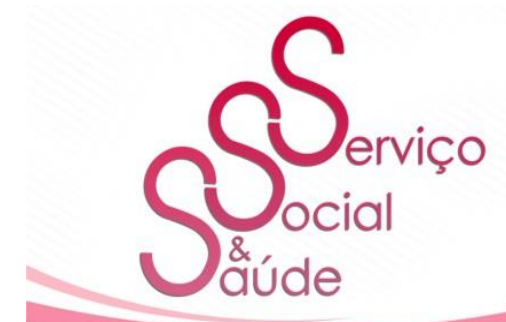

ISSN 2446-5992

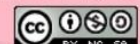

10.20396/sss.v20i00.8665391

narrativas capazes de potencializar vulnerabilidades. Em terceiro, as controvérsias sobre o uso de dados em tecnologias digitais para o combate à pandemia, quanto a questões éticas e legais relacionadas a esse processo. Essas questões se somam e são intensificadas pela conturbada condução da pandemia no Brasil, marcada desarticulação das decisões e aplicação de medidas entre as esferas de governo, o que resultou em evolução ascendente do novo coronavírus (IPEA, 2021).

Dessa forma, as sociabilidades se manifestam em comportamentos individuais, na forma de representações sociais que se desenvolvem no âmbito da esfera pública. Como pontuou Nunes (2020, p. 2), "a história dessa pandemia é feita de dinâmicas socioeconômicas e culturais no nível da organização do trabalho e das relações sociais".

$\mathrm{Na}$ análise realizada, percebe-se que há diferentes tratamentos sobre a questão de segurança digital, sob diferentes perspectivas. Enquanto a exposição da intimidade para reprodução individual de narrativas é amplamente aceita, a possibilidade de uso de dados para tecnologias de monitoramento da população é vista como uma forma de controle a ser repelida. Essas aparentes contradições entre público e privado no uso da imagem e de dados, na verdade revelam tensões permanentes do modo capitalista que, em sua abordagem neoliberal, pauta-se na promoção do individualismo acima de quaisquer valores coletivos. Dessa forma, as ações e relações cotidianas são profundamente marcadas por escolhas de um modelo político-econômico que legitima o culto ao 'eu' e enfraquece redes de solidariedade e empatia.

Neste momento de fragilidade global, o culto ao eu-patenteado e à performance, o ideal neoliberal do indivíduo conquistador repleto de símbolos de sucessos determinados unicamente por sua própria ação (BENDASSOLI, 2000), esbarra-se com as múltiplas vulnerabilidades e crescentes danos de diversas ordens provocadas pela pandemia. Ainda assim, no contexto brasileiro, de democracia frágil e instabilidade política, prevalecem as narrativas contrárias às medidas de enfrentamento do problema.

Nesse sentido, as questões sobre representações sociais manifestadas em mídias sociais e outros espaços digitais, apontam para a importância de estabelecer políticas de 


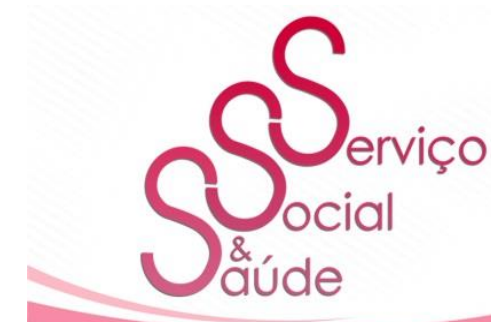

ISSN 2446-5992

(c) 10 (2)

10.20396/sss.v20i00.8665391

informação e comunicação, na perspectiva de vigilância em saúde, que possibilitem a construção de uma participação da sociedade que esteja assentada na solidariedade e em contribuições efetivas para a solução dos problemas coletivos.

\section{REFERÊNCIAS}

ALMEIDA, B. de A. et al. Preservação da privacidade no enfrentamento da COVID-19: dados pessoais e a pandemia global. Ciência \& Saúde Coletiva, v. 25, suppl 1, pp. 2487 2492, jun 2020. Disponível em:

<http://www.scielo.br/scielo.php?script=sci_arttext\&pid=S1413-

$81232020006702487 \& \operatorname{lng}=$ en\&nrm=iso $>$. Acesso em 10 mar 2021.

BENDASSOLLI, P. F. Público, privado e o indivíduo no novo capitalismo. Tempo soc., São Paulo, v. 12, n. 2, p. 203-236, nov 2000. Disponível em:

$<$ http://www.scielo.br/scielo.php?script=sci_arttext\&pid=S0103-

$20702000000200014 \& \operatorname{lng}=$ en\&nrm=iso > . Acesso em 10 mar 2021.

BORLINI, L. M. Há pedras no meio do caminho do SUS - os impactos do neoliberalismo na saúde do Brasil. Textos \& Contextos (Porto Alegre), v. 9, n. 2, p. 321 - 333, ago/dez. 2010. Disponível em: <https://revistaseletronicas.pucrs.br/ojs/index.php/fass/article/view/7697>. Acesso em 10 mar 2021.

BOULLOSA, R. F.; PERES, J. L.; LARANJA, L. L.; SILVA, L. G. Subtração da Gestão de Políticas Públicas no Contexto Pandêmico: os desdobramentos de um desamparo público agravado pela Covid-19. Revista Interdisciplinar de Gestão Social, v. 10, n. 1, jan/abr 2021. Disponível em: <https://periodicos.ufba.br/index.php/rigs/article/view/39296>. Acesso em 10 $\operatorname{mar} 2021$.

BUCCO, Rafael. Geolocalização: suspensão de acordo entre MCTIC e teles não afeta programas regionais. Tele.Síntese, 13 abril 2020. Disponível em <https://www.telesintese.com.br/geolocalizacao-suspensao-de-acordo-entre-mctic-e-telesnao-afeta-programas-regionais/>. Acesso em 10 mar 2021.

CALIL, G. G. A negação da pandemia: reflexões sobre a estratégia bolsonarista. Serv. Soc. 


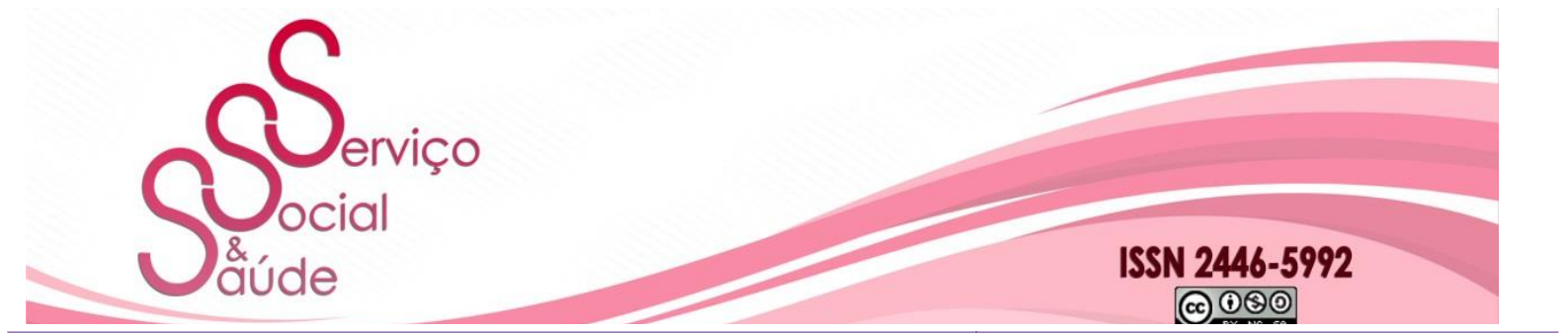

10.20396/sss.v20i00.8665391

Soc., São Paulo, n. 140, p. 30-47, Apr. 2021.

GRASSI, J. M.; PINTO, D. J. O uso dos dados de geolocalização da população na prevenção e combate ao COVID-19 e as implicações pós-pandemia. Rede CTIDC Pró Defesa IV Ciência, Tecnologia e Inovação em Defesa: cibernética e defesa nacional. Disponível em: $<$ https://redectidc.com.br/assets/files/COVID-19--

Usodadosgeolocalizacaonaprevencaoecombateeasimplicacoespos-pandemia.pdf $>$. Acesso em 10 mar 2021.

INSTITUTO DE PESQUISA ECONÔMICA APLICADA - IPEA. Nota técnica $\mathbf{n}^{\mathbf{0}}$ 21: oito meses de pandemia no Brasil: medidas para o enfrentamento federativo e perspectivas com as vacinas. Brasília, 2021.

JOVCHELOVITCH, S. Representações sociais e esfera pública: a construção simbólica dos espaços públicos no Brasil. Petrópolis: Vozes, 2000.

JUNQUEIRA, T.; CHALFIN, R. COVID-19 e postergação da LGPD: histeria ou sabedoria?

Consultor Jurídico. Disponível em: <https://www.conjur.com.br/2020-abr-21/opiniao-covid19-postergacao-lgpd-histeria-ou-sabedoria\#sdfootnote4sym>.

LEAL-NETO, O.; DIMECH, G. S; LIBEL, M. et al. Digital disease detection and participatory surveillance: overview and perspectives for Brazil. Rev. Saúde Pública, São Paulo, v. 50, 17, 2016. Disponível em:

$<$ http://www.scielo.br/scielo.php?script=sci_arttext\&pid=S0034-

$89102016000100702 \& \operatorname{lng}=$ en\&nrm=iso >. Acesso em 11 mar. 2021.

LIMA, N. T.; BUSS, P. M.; PAES-SOUSA, R. A pandemia de COVID-19: uma crise sanitária e humanitária. Cad. Saúde Pública, Rio de Janeiro, v. 36, n. 7, 2020.

LOCH, J. A; CLOTET, J. ; GOLDIM, J. R. Privacidade e confidencialidade na assistência à saúde do adolescente: percepções e comportamentos de um grupo de 711 universitários. Rev. Assoc. Med. Bras. São Paulo, v. 53, n. 3, p. 240-246, June 2007. Disponível em:

$<$ http://www.scielo.br/scielo.php?script=sci_arttext\&pid=S0104$42302007000300022 \& \operatorname{lng}=\mathrm{en} \& \mathrm{nrm}=\mathrm{iso}>$. Acesso em 11 mar. 2021.

MARTORELL, L. B.; NASCIMENTO, W. F. do; GARRAFA, V. Redes sociais, privacidade, confidencialidade e ética: a exposição de imagens de pacientes no facebook. Interface 


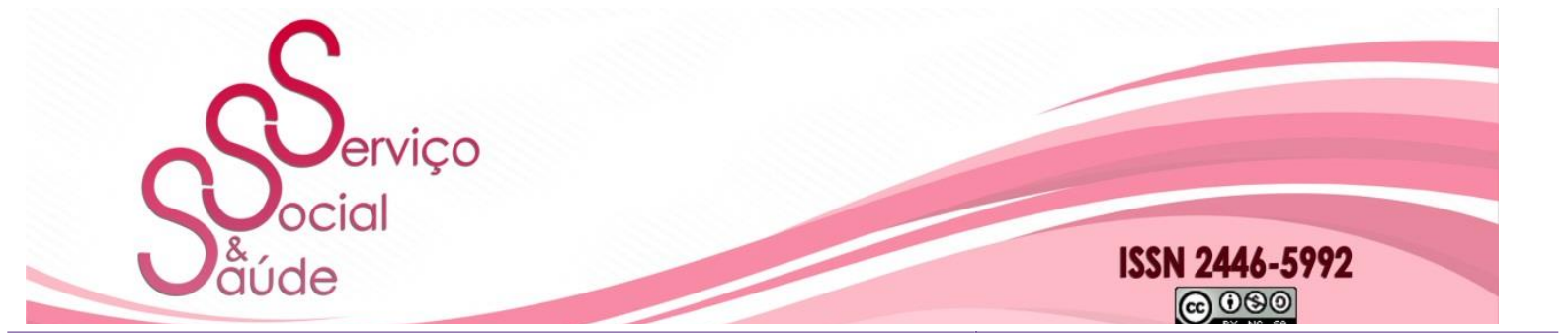

10.20396/sss.v20i00.8665391

(Botucatu), Botucatu, v. 20, n. 56, p. 13-23, mar 2016.

MATTOS, A. R.; CASTRO, L. R. Jovens e a liberdade: reflexões sobre autonomia, responsabilidade e independência. Psicol. Soc., Belo Horizonte, v. 28, n. 1, p. 65-73, abr. 2016. Disponível em: <http://www.scielo.br/scielo.php?script=sci_arttext\&pid=S0102$71822016000100065 \& \operatorname{lng}=\mathrm{en} \& \mathrm{nrm}=\mathrm{iso}>$. Acesso em $11 \mathrm{mar} .2021$.

MEDEIROS, M. S. Apontamentos sobre as modalidades de intervenção social no enfrentamento das lesões e mortes causadas por acidentes de trânsito relacionados ao consumo de bebida alcoólica. Saude soc., São Paulo, v. 26, n. 2, p. 556-570, jun 2017. Disponível em: <http://www.scielo.br/scielo.php?script=sci_arttext\&pid=S010412902017000200556\&lng=en\&nrm=iso>. Acesso em 11 mar. 2021.

NUNES, J. A pandemia de COVID-19: securitização, crise neoliberal e a vulnerabilização global. Cadernos de Saúde Pública, v. 36, n. 5, maio 2020. Disponível em: $<$ http://www.scielo.br/scielo.php?script=sci_arttext\&pid=S0102311X2020000500501\&lng=en\&nrm=iso>. Acesso em: 11 mar. 2021. RIBEIRO, G. L. Medo Global. Boletim Cientistas Sociais, n 5, 26/03/2020. Disponível em <http://www.anpocs.com/index.php/ciencias-sociais/destaques/2311-boletim-n-3>. Acesso em 09 mar 2021.

ROSA, C. B.; LUIZ, D. E. Democracia: tipologia, relações e expressões contemporâneas. Aurora, ano V, número 8, agosto de 2011. Disponível em: <https://revistas.marilia.unesp.br/index.php/aurora/article/view/1267>. Acesso em: 11 mar. 2021.

SAMAJA, J. Epistemologia de la salud: reprodução social, subjetividade e transdisciplina. Buenos Aires: Lugar; 2004.

STF SUSPENDE eficácia de MP sobre compartilhamento de cadastros telefônicos com o IBGE. Câmara dos Deputados. Disponível em: < https://www.camara.leg.br/noticias/660343-stf-suspende-eficacia-de-mp-sobrecompartilhamento-de-cadastros-telefonicos-com-o-ibge/>. Acesso em 09 mar 2021. THIBES, M. Z. As formas de manifestação da privacidade nos três espíritos do capitalismo: da intimidade burguesa ao exibicionismo de si nas redes sociais. Sociologias, v. 19, n. 46, p. 


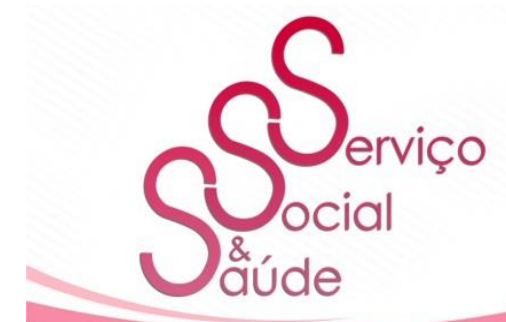

\section{ISSN 2446-5992}

(c) (1)(-)

10.20396/sss.v20i00.8665391

316-343, dez 2017. Disponível em: <

http://www.scielo.br/scielo.php?script=sci_arttext\&pid=S1517-

45222017000300316\&lng=en\&nrm=iso>. Acesso em: 11 mar. 2021.

PROGRAMA CONJUNTO DAS NAÇÕES UNIDAS SOBRE HIV/AIDS (UNAIDS).

Abordando estigma e discriminação na resposta à COVID-19. Brasil: UNAIDS, 2020.

Disponível em: <https:/unaids.org.br/wp-content/uploads/2020/11/covid19-stigma-

brief_Portuguese_Final.pdf>.Acesso em: 12 mar. 2021.

SANTOS, M. P. A. dos.; et al. População negra e Covid-19: reflexões sobre racismo e saúde.

Estud. av., São Paulo, v. 34, n. 99, p. 225-244, Aug. 2020. Disponível em:

$<$ http://www.scielo.br/scielo.php?script=sci_arttext\&pid=S0103-

$40142020000200225 \& \operatorname{lng}=\mathrm{en} \& \mathrm{nrm}=\mathrm{iso}>$. Acesso em: 12 mar. 2021.

YNOUB, R.; SAMAJA, J. Monitoreo de ambientes de desarrollo humano. Condições de vida e salud. In: Anais do VII Congreso de la Associacion Latinoamericana de Medicina

Social, Buenos Aires: Asociación Latinoamericana de Medicina Social, 1997. 